\title{
Fast and Accurate Electrochemical Measurement of Total Antioxidant Capacity as an Alternative to Spectrophotometrical Methods
}

\author{
Susana Rey ${ }^{1}$, Esther Gómez ${ }^{1}$, Henar Muñoz-Cimadevilla ${ }^{1}$ and David Hevia*1,2 \\ ${ }^{1}$ Research and Development Department, Spain \\ ${ }^{2}$ Morphology and Cell Biology Department, Redox Biology Group, Spain
}

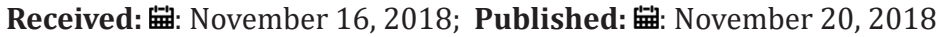

*Corresponding author: David Hevia, Research and Development Department, Morphology and Cell Biology Department, Redox Biology Group, Oviedo, Spain

\begin{abstract}
Total Antioxidant Capacity or TAC is an indicator of the sample ability to scavenge free radicals despite its complex composition. It has been measured in biological fluids as an inverse biomarker of oxidative stress, which has been related to disease. Classical spectrophotometric methods present some limitations including sample pretreatment required leading to long assay procedures, native $\mathrm{pH}$ alteration, low stability of some reagents, high detection limits, low sensitivity and sample's colour interference. Various electrochemical techniques have raised as more precise alternatives that overcome most of the limitations in classical methodologies and have been gaining popularity specially for food and beverage analysis. In this mini review, an electrochemical measurement of antioxidant capacity with applications in vitro and in vivo is presented.
\end{abstract}

Keywords: Total Antioxidant Capacity; Electrochemical; Voltammetry; Biological samples; Oxidative stress

Abbreviations: TAC: Total Antioxidant Capacity; TEAC: Trolox Equivalent Antioxidant Capacity, GAE: Gallic Acid Equivalents; CEAC: Vitamin C Equivalents Antioxidant Capacity

\section{Introduction}

Antioxidants are compounds that neutralize free radicals, very toxic by-products of cell metabolism, and so preventing the damage that they cause. This ability, which is usually referred to as total antioxidant capacity or TAC, depends on different parameters, for example, antioxidant concentration, molecular weight and the synergies among them [1]. The antioxidant capacity is an increasingly interesting biomarker since it is inversely proportional to oxidative stress.

\section{Classic Methods}

With the aim of determining the TAC of a sample, more than 25 assays have been developed until date [2]. They can be classified into direct (when a free radical is used) or indirect (if the reaction does not involve a free radical) [3]. In general, the basis of these assays is to put the sample in contact with a compound, which absorbs at a specific wavelength either in its oxidized or reduced form. Then, a measure of the absorbance gives the amount of the compound reduced by the sample. This antioxidant capacity is typically referred to the concentration of a model antioxidant like Trolox, gallic acid or ascorbic acid giving the following units: TEAC (Trolox Equivalent Antioxidant Capacity), GAE (Gallic Acid Equivalents) or CEAC (Vitamin C Equivalents Antioxidant Capacity). However, while many methods have been described, they still present some limitations. Firstly, the pH, solvents and temperatures set for the assay are usually different from the native conditions of the sample, and so antioxidant capacity may be affected [4]. Secondly, the size and complexity of the indicator affect the binding ability of the antioxidants, and so the larger and complex the indicator compound is, the higher the probability of underestimating the sample's TAC [5]. In addition, some key antioxidants cannot be measured with some of the classic techniques, like glutathione [6]. Finally, the combination of all the factors mentioned above, make antioxidant capacity obtained with the different methodologies not comparable among them, even if they were measured with the same units [7].

\section{Electrochemical Methods}

Electrochemistry is a very sensitive and reproducible technique that has been already described as a powerful alternative to 
classical spectrophotometric methodologies [8]. It allows a quick measurement of TAC without modifying sample native conditions and could potentially be established as a standardized measurement of antioxidant capacity that overcomes the drawbacks of intercomparisons and uses an international system derivative unit for antioxidant capacity. From all the electrochemical methods, the most used are voltammetry, bioamperometry, amperometry, potentiometry and coulometry. Since those methods present lower detection limits, higher sensitivity and quickness, they have been gaining popularity in recent years, especially in the beverage's analysis field [9] (mainly wine [10-15], tea [16,17] and juice [10,1820]) rather than in biological samples (urine [21,22], plasma [23-25] and blood $[26,27])$. The present portable device and voltammetric method comprises the application of increasing potentials and the measurement of the intensity of the current at each one. In this way, a complete oxidation of the sample is carried out. Individual peaks are considered the response of a specific antioxidant and through a mathematic algorithm a measure of the total antioxidant capacity of the sample obtained and expressed in micro-coulombs. The total charge of antioxidants is divided in two sections, from which the ones at a lower potential of oxidation are considered the fast and the others the slow antioxidants.

\section{Conclusion}

The measurement of TAC with electrochemical methods have already been described. However, they are not widely used within the scientific community. This new promising voltammetric method can be used at physiological $\mathrm{pH}$, leading to a total determination of antioxidant capacity, with potential applications both in vitro and in vivo. Moreover, it is able to distinguish between slow and fast antioxidants, an interesting feature not present in other TAC assays.

\section{Acknowledgement}

This work was supported by grants from Economic Development Agency of the Principality of Asturias (IDEPA). S.Rey acknowledge to MINECO (DI-16-08911).

\section{References}

1. Young IS (2001) Measurement of total antioxidant capacity. J Clin Pathol 54(5): 339-339.

2. Alam MN, Bristi NJ, Rafiquzzaman M (2013) Review on in vivo and in vitro methods evaluation of antioxidant activity. Saudi Pharm J SPJ 21(2): 143-152.

3. Pisoschi AM, Negulescu GP (2012) Methods for Total Antioxidant Activity Determination: A Review. Biochem Anal Biochem 1: 106.

4. Dawidowicz AL, Wianowska D, Olszowy M (2012) On practical problems in estimation of antioxidant activity of compounds by DPPH method (Problems in estimation of antioxidant activity). Food Chem 131(3): 1037-1043.

5. Schaich KM, Tian X, Xie J (2015) Hurdles and pitfalls in measuring antioxidant efficacy: A critical evaluation of ABTS, DPPH, and ORAC assays. J Funct Foods 14: 111-125.

6. Apak R, Çapanoğlu E, Shahidi F (2018) Measurement of antioxidant activity and capacity: recent trends and applications. In: Apak R
Çapanoğlu E, Shahidi F (Eds.). (1 ${ }^{\text {st }}$ edn); Hoboken, New Jersey, United States, p. 1.

7. Schlesier K, Harwat M, Böhm V, Bitsch R (2002) Assessment of antioxidant activity by using different in vitro methods. Free Radic Res 36(2): 177-187.

8. Pisoschi AM, Cimpeanu C, Predoi G (2015) Electrochemical Methods for Total Antioxidant Capacity and its Main Contributors Determination: A review. Open Chem 13(1).

9. Hoyos Arbeláez J, Vázquez M, Contreras Calderón J (2017) Electrochemical methods as a tool for determining the antioxidant capacity of food and beverages: A review. Food Chem 221: 1371-1381.

10. Milardovic S, Kereković I, Derrico R, Rumenjak V (2007) A novel method for flow injection analysis of total antioxidant capacity using enzymatically produced ABTS*+ and biamperometric detector containing interdigitated electrode. Talanta 71(1): 213-220.

11. Photinon K, Chalermchart Y, Khanongnuch C, Wang SH, Liu CC (2010) A Thick-film Sensor as a Novel Device for Determination of Polyphenols and Their Antioxidant Capacity in White Wine. Sensors 10(3): 16701678.

12. Aguirre MJ, Chen YY, Isaacs M, Matsuhiro B, Mendoza L, et al. (2010) Electrochemical behaviour and antioxidant capacity of anthocyanins from Chilean red wine, grape and raspberry. Food Chem 121(1): 44-48.

13. Souza LP, Calegari F, Zarbin AJG, Marcolino Júnior LH, Bergamini MF (2011) Voltammetric Determination of the Antioxidant Capacity in Wine Samples Using a Carbon Nanotube Modified Electrode. J Agric Food Chem 59(14): 7620-7625.

14. Jakubec P, Bancirova M, Halouzka V, Lojek A, Ciz M, et al. (2012) Electrochemical sensing of total antioxidant capacity and polyphenol content in wine samples using amperometry online-coupled with microdialysis. J Agric Food Chem 60(32): 7836-7843.

15. Sánchez Arribas A, Martínez Fernández M, Moreno M, Bermejo E, Zapardiel A, et al. (2013) Analysis of total polyphenols in wines by FIA with highly stable amperometric detection using carbon nanotubemodified electrodes. Food Chem 136(3-4): 1183-1192.

16. Campanella L, Martini E, Rita G, Tomassetti M (2006) Antioxidant capacity of dry vegetal extracts checked by voltammetric method. J Food Agric Environ 4(1).

17. Piljac Žegarac J, Valek L, Stipčević T, Martinez S (2010) Electrochemical determination of antioxidant capacity of fruit tea infusions. Food Chem 121(3): 820-825.

18. Blasco AJ, González MC, Escarpa A (2004) Electrochemical approach for discriminating and measuring predominant flavonoids and phenolic acids using differential pulse voltammetry: towards an electrochemical index of natural antioxidants. Anal Chim Acta 511(1): 71-81.

19. Pisoschi AM, Cheregi MC, Danet AF (2009) Total antioxidant capacity of some commercial fruit juices: electrochemical and spectrophotometrical approaches. Mol Basel Switz 14(1): 480-493.

20. Bordonaba JG, Terry LA (2012) Electrochemical behaviour of polyphenol rich fruit juices using disposable screen-printed carbon electrodes: towards a rapid sensor for antioxidant capacity and individual antioxidants. Talanta 90: 38-45

21. Adam V, Mikelova R, Hubalek J, Hanustiak P, Beklova M, et al. (2007) Utilizing of Square Wave Voltammetry to Detect Flavonoids in the Presence of Human Urine. Sensors 7(10): 2402-2418.

22. Cao T, He M, Bai T, Liu H (2016) Establishment of a Method for Measuring Antioxidant Capacity in Urine, Based on Oxidation Reduction Potential and Redox Couple I 2 /KI. Bioinorg Chem Appl 2016: 1-9. 
23. Chevion S, Berry EM, Kitrossky N, Kohen R (1997) Evaluation of plasma low molecular weight antioxidant capacity by cyclic voltammetry. Free Radic Biol Med 22(3): 411-421.

24. Chevion S, Roberts MA, Chevion M (2000) The use of cyclic voltammetry for the evaluation of antioxidant capacity. Free Radic Biol Med 28(6): 860-870.

25. Ziyatdinova GK, Budnikov HC, Pogorel'tzev VI (2005) Electrochemical determination of the total antioxidant capacity of human plasma. Anal Bioanal Chem 381(8): 1546-1551.

\section{ISSN: 2574-1241}

DOI: 10.26717/BJSTR.2018.11.002069

David Hevia. Biomed J Sci \& Tech Res

(c) (i) This work is licensed under Creative

Submission Link: https://biomedres.us/submit-manuscript.php
26. Ziyatdinova GK, Voloshin AV, Gilmutdinov AK, Budnikov HC, Ganeev TS (2006) Application of constant-current coulometry for estimation of plasma total antioxidant capacity and its relationship with transition metal contents. J Pharm Biomed Anal 40(4): 958-963.

27. Ziyatdinova GK, Budnikov HC, Pogorel'tzev VI, Ganeev TS (2006) The application of coulometry for total antioxidant capacity determination of human blood. Talanta 68(3): 800-805.

\begin{tabular}{ll} 
BIOMEDICAL & Assets of Publishing with us \\
RESEARCHES & - Global archiving of articles \\
\hline IsS: $2574-1241$ & - Immediate, unrestricted online access \\
& - Aigorous Peer Review Process \\
\hline
\end{tabular}

